\title{
Congenital obstructive posterior urethral membranes and recurrent urinary tract infection: a rare case of congenital hypertrophy of the verumontanum
}

\author{
Diana Bancin, Elisabeth S. Herini, Pungky Ardani Kusuma, Neti Nurani
}

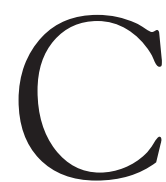

ongenital obstructive posterior urethral membranes (COPUM) is a complex disease closely related to several pathological changes in kidney development and function, as a result of urinary reflux since in utero. This congenital anomaly of urinary tract potentially causes hydroureteronephrosis that is often associated with recurrent urinary tract infections and, ultimately, one of the most common causes of end-stage renal disease in children. ${ }^{1,2}$ Congenital hypertrophy of the verumontanum as part of COPUM is very rare. Only a few reports have been written on congenital hypertrophy of the vermontanum causing congenital obstructive uropathy. ${ }^{3-6}$

\section{The Case}

A boy, 4 month old, came to Dr. Sardjito Hospital with the chief complaint of abdominal bloating and difficulty urinating. From his medical history, it was known that the child had experienced a good labor and had been discharged from hospital post-natal care. The parents felt that the child urinated frequently but small volumes. The child did not appear to strain or experience pain when urinating, the tip of the penis did not inflate while urinating, and the child did not have fever. The complaints persisted until the age of 4 months, when the child's weight did not increase with age, his abdomen began to enlarge and sometimes a lump was palpable in his lower abdomen.

On physical examination, the child was afebrile and normotensive. The abdomen looked distended and a palpable mass was found in the suprapubic region. The child was ballotement $(+)$ and he was severely underweight, stunted, and considered as failure to thrive (FTT). There was no phimosis, but the conjunctivae appeared pale (anemic).

The peripheral blood examination showed mild hypochromic microcytic anemia $(\mathrm{Hb} 9.4 \mathrm{~g} / \mathrm{dL})$ and leukocytosis with neutrophil predominance (leukocyte count $31,000 / \mathrm{mm}^{3}$ with neutrophils $75.9 \%$ ). The result of urinalysis suggested a urinary tract infection, with leukocyte esterase $250 \mathrm{IU} / \mathrm{L}$, pale leukocyte ++ , dark leukocytes ++ , proteinuria $(+2)$, and hematuria (erythrocytes +3 ). Urine culture results indicated the presence of Pseudomonas aeruginosa infection (bacterial count $10^{7} \mathrm{cfu} / \mathrm{mL}$ ). His blood urea nitrogen level was $32.8 \mathrm{mg} / \mathrm{dL}$ and creatinine was $0.59 \mathrm{mg} /$ $\mathrm{dL}$ (calculated glomerular filtration rate was $44 \mathrm{~mL}$ / $\mathrm{min} / 1.73 \mathrm{~m}^{2}$ ), which suggested acute kidney injury (AKI) risk phase, based on RIFLE criteria. ${ }^{7}$

From the Department of Child Health, Gadjah Mada University Medical School/Dr. Sardjito Hospital, Yogyakarta, Indonesia.

Reprint requests to: Diana Bancin, Division of Nephrology, Department of Child Health, Gadjah Mada University Medical School/Dr. Sardjito Hospital, Jl. Kesehatan No.1 Sekip, Yogyakarta. Tel +62-274-587333. Email: dbancin@yahoo.com. 
The abdominal USG showed bilateral hydronephrosis with a differential diagnosis of bilateral polycystic renal disease and suggested the presence of a mass behind the urinary bladder (Figure 1). Abdominal CT scan revealed a bilateral hydronephrosis, a hydroureter with elongated ureter, the bladder filled with liquid so as to appear enlarged, but no tumors were seen, suggesting the presence of posterior urethral valve (Figure 2).

A voiding cystourethrogram (VCUG) revealed cystitis, multiple diverticula, bilateral vesicoureteral reflux (VUR) grade $\mathrm{V}$, bilateral hydronephrosis grade IV-V, and bilateral hydroureter. These findings were likely caused by chronic obstruction of the distal bladder (Figure 3). Urethroscopy and cystoscopy
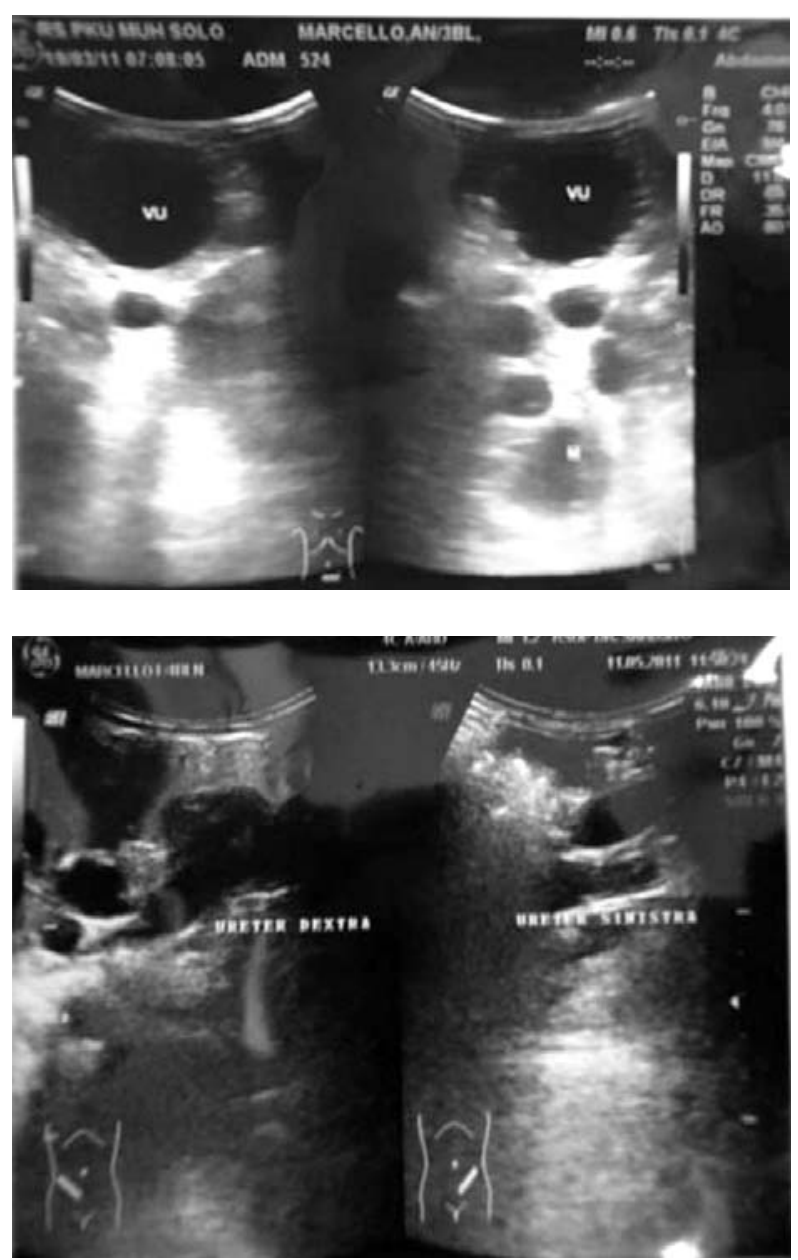

Figure 1. Abdominal USG revealed bilateral hydronephrosis with differential diagnosis of bilateral polycystic renal disease (possible a mass behind the bladder) revealed no obstructive valves, but did show congenital hypertrophy of the verumontanum as a potential cause of obstruction. Therefore, we concluded that the child had congenital obstructive posterior urethral membranes (COPUM), because of congenital hypertrophy of the verumontanum (Figure 4). Partial transurethral resection of verumontanum was performed at that time. The result of the postresectional anatomical pathology showed connective tissue fragments with tubular and papillary forms of glandular, cellular stroma with fibrotic parts. There was no malignancy. We concluded that the child had chronic inflammation with fibrosis.

Based on the clinical data, the patient was diagnosed with COPUM due to congenital hypertrophy of the verumontanum post-partial transurethral resection, complex urinary tract infection due to Pseudomonas aeruginosa, bilateral hydronephrosis grade IV-V, bilateral hydroureter, VUR grade V, impaired renal function, and microcytic hypochromic anemia due to renal disease.

During subsequent 14 months of monitoring, the child had recurrent urinary tract infections with symptoms of fever, decreased appetite, irritability, and vomiting. Urinary tract infection was established by way of routine urinalyses, indicated by the presence of leukocyte esterase $500 \mathrm{IU} / \mathrm{L}$, pale leukocytes and dark leukocytes. Urine culture showed infection with Pseudomonas aeruginosa (bacterial count $10^{6} \mathrm{cfu} / \mathrm{mL}$ ). Proteinuria and hematuria disappeared within 5 months of monitoring. During monitoring, the effect of prophylactic antibiotic to prevent recurrent episodes of urinary tract infections could not be assessed due to lack of compliance in taking the medication. There continued to be poor growth acceleration during the monitoring period, such that the child was severely underweight. His nutritional status was likely associated with acute infections (even though at the end of monitoring the child was able to catch up in growth). The child's linear growth up to 2 years of age also seemed poor, with a slow increase, though by the end of the monitoring there was a considerable growth increase. Four months after the partial resection, the child had good increase in length, but overall, his body length was not appropriate for his age and at the end of monitoring the child was considered to be stunted (short stature). The child had suffered from malnutrition, but eventually achieved a good nutritional status. 
The child had gross developmental motor delay 5 months after resection. After undergoing general physiotherapy, the delay was corrected and the child had normal development appropriate for his age by the end of the monitoring period.

One year after the partial resection, the child was suspected of having a recurrent obstruction, with symptoms of abdominal bloating, a palpable mass in the abdomen, frequent urination with small voided urine volume, difficulty urinating, and nocturia. In addition, the ultrasound evaluation revealed a change from bilateral grade II hydronephrosis to grade III hydronephrosis. Furthermore, the VCUG results showed a left grade V VUR, open bladder neck with less smooth micturition flow, and a possible urethral obstruction. Due to family issues, urethroscopy

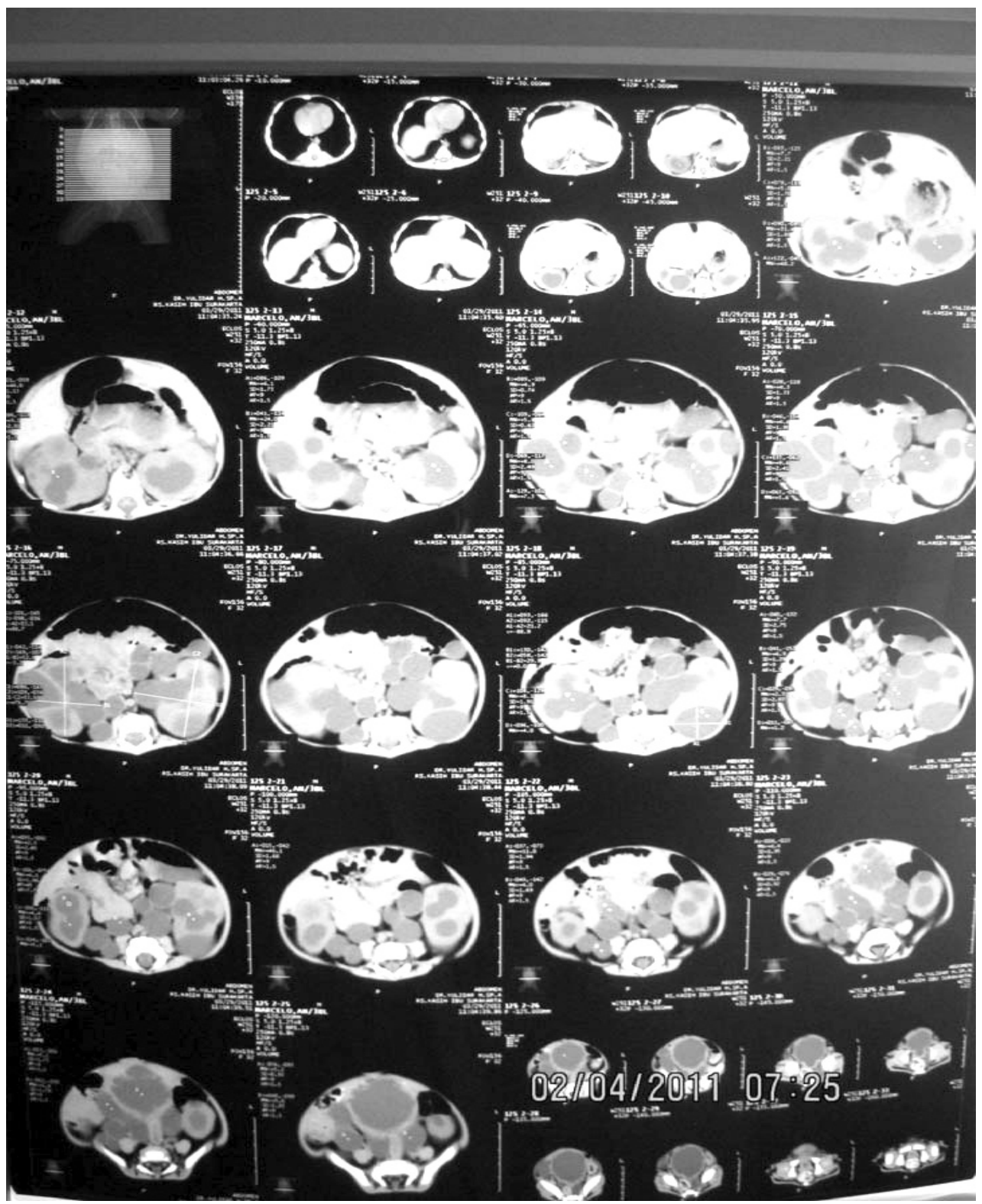

Figure 2. Abdominal CT scan of bilateral hydronephrosis, hydroureter with elongated ureter, vesica urinaria filled with liquid so that it appears to be enlarged. No tumors seen. Evidence suggestive of urethral posterior valve. 


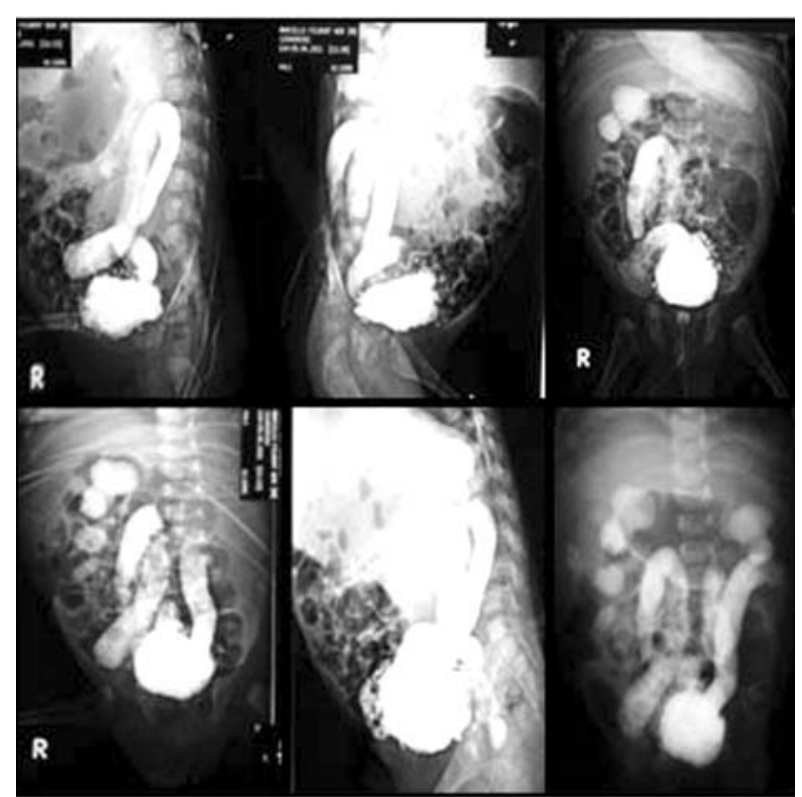

Figure 3. VCUG revealed obstruction in distal bladder, hydronephrosis, and hydroureter
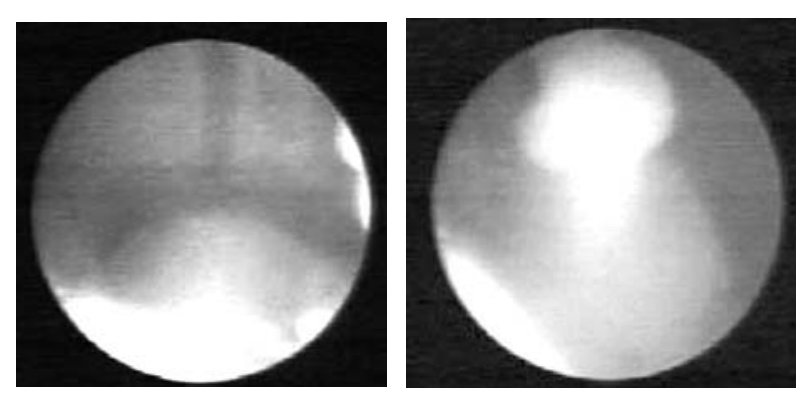

Figure 4. Congenital hypertrophy of verumontanum

could only be done 10 months later, with the results showing the presence of a bladder neck contracture. Transurethral resection (TUR) of the contracture was subsequently performed through urethroscopy.

\section{Discussion}

Congenital obstructive posterior urethral membranes is the most common cause of urinary tract obstruction in boys. These pathological conditions arise in a range of clinical forms from mild to very severe clinical conditions involving impaired renal function. This obstructive lesion of COPUM has been reported to occur in 1,000-2,000 births, with bilateral characteristics in $20-25 \%$ of cases, and a predominance in boys at a ratio of $3: 1 .^{8}$ The most common cause of COPUM is the posterior urethral valve (incidence 1:8,000), while congenital hypertrophy of the verumontanum is one of the rarest urinary tract anomalies found. This condition was first noted in post-mortem reports, but as diagnostic tools inproved, there were a few reported living cases with this condition. ${ }^{3-5}$

Urologic abnormalities may increase the risk and be the cause of urinary tract infections in children. These abnormalities are often recognized late, mostly when the child has had recurrent urinary tract infections (UTIs). ${ }^{9}$ Vesicoureteral reflux, recurrent urinary tract infections, voiding disorders, and chronic kidney disease are long-term problems in these patients. ${ }^{10}$

In this case, the child had experienced some complications, including recurrent UTIs. Congenital hypertrophy of the verumontanum is not a direct risk factor for UTI, but it increases the risk of disruption of the normal voiding process, leading to increased risk of lower urinary tract infections (e.g., bladder and urethral infections). These infections may eventually ascend to the upper urinary tract, leading to pyelonephritis and renal dysfunction. Pediatric urinary tract malformations have been associated with a high incidence of uropathogens and uropathogenic, multidrug-resistant non-E. coli bacteria, particularly Pseudomonas and Enterococcus, such as in our patient. ${ }^{11}$ Uropathogens often hide in locations unaffected by antimicrobial therapy. Identification of anatomical abnormalities and correction of the anatomy in congenital hypertrophy of the verumontanum are very important in order to address the source of infection. ${ }^{12}$

Another complication in our patient was his VUR. Vesicoureteral reflux is a risk factor for recurrent UTI and renal scarring, while recurrent UTI itself is also a risk factor for renal scarring. ${ }^{3-15}$ Renal scarring presents in $9.5-38 \%$ of children with VUR, $12 \%$ of all UTI cases, and $25 \%$ of children with recurrent UTI. There may also be increased risk of irreversible renal parenchymal damage, thus requiring long-term follow-up. ${ }^{16,17}$

The patient was treated only with partial transurethral resection of the verumontanum, so he remains at risk for recurrent obstructions. In fact, 
the child suffered from a recurrent obstruction with a definitive diagnosis of bladder neck contracture, which has been known to occur in $2 \%$ of postoperative obstructive uropathies, due to the loop endoscopy itself. ${ }^{18}$

Our patient suffered from acute kidney injury when he initially presented, and failure to thrive during the monitoring, but unfortunately, his bladder function status was unknown. Risk factors for renal failure are VUR obstructive urinary tract disorders, non-E. coli infectious etiologies, and infection in infants and young chidren. ${ }^{1,19,20}$ Children with obstructive uropathy have a $24-25 \%$ risk of kidney failure, $30 \%$ of failure to thrive, and $30 \%$ of poor bladder function. These conditions are closely related to low glomerular filtration rate (GFR) and severe metabolic acidosis. ${ }^{21}$

Some experts are of the opinion that recurrent UTIs in the presence of complicating factors such as anatomical urinary tract abnormalities, should be treated with prophylactic antibiotics, but the effects of this treatment remain unclear. ${ }^{22}$ Conway et al. stated that antibiotic prophylaxis was associated with increased urinary tract infections resistant to antibiotics. ${ }^{23}$ Some experts suggest the use of prophylactic antibiotics if the child has VUR, immunosuppression, partial urinary tract obstruction, recurrent UTIs with normal renal function, two episodes of UTIs within 6 months, or 3 episodes within 12 months, as in our patient. ${ }^{18,24,25}$ In a 2011 metaanalysis, the long-term use of prophylactic antibiotics did not significantly reduce the number of recurrent UTIs, but was able to decrease the risk of new kidney damage, with number needed to treat (NNT) of 33 in $2-3$ years. ${ }^{26}$

The prognosis in congenital obstructive conditions depends on compliance to therapy, renal function before and after correction of the obstruction, age at diagnosis, the presence of VUR at the time of diagnosis, accompanying UTIs, proteinuria, hypertension and the initial therapy given to the patient. ${ }^{27,28}$ All of these factors are helpful to predict the progression of the disease and determine a long-term prognosis. ${ }^{28,29}$

Pediatric specialists and urologists should recognize the possibility of rare anomalous conditions, as well as the possibility of subsequent complications. Diagnosis of congenital hypertrophy of the veru- montanum is difficult. There are no typical clinical symptoms, though imaging can help in assessing the possibility of congenital hypertrophy of the verumontanum. Long-term follow up is needed in every case.

\section{References}

1. Ansari MS, Singh P, Mandani A, Dubey D, Srivatava A, Kapoor R, et al. Delayed presentation posterior urethral valve: long-term implications and outcome. Urology. 2008;71:2304.

2. Sanna-Cherchi S, Ravani P, Corbani V, Parodi S, Haupt R, Piaggio G, et al. Renal outcome in patients with congenital anomalies of the kidney and urinary tract. Kidney Int. 2009; 76:528-33.

3. Bapna BC, Reddy AV, Wadhwa SN. Hypertrophied verumontanum producing urinary obstruction. Indian J Pediatr. 1970;37:155-7.

4. Ohkawa T, Nakamura M. Congenital hypertrophy of the verumontanum: report of a case. Hinyokika Kiyo. 1963;9:321-5.

5. Kilciler M, Soydan H, Ozgok Y, Erduran D, Harmankaya C. A rare cause of urethral obstruction: verumontanum attachment. J Urol. 2001;166:1401-3.

6. Baldridge, RR. A case of congenital hypertrophy of the verumontanum. N Engl J Med. 1935;213:46-9.

7. Alatas H. Gagal ginjal akut. In: Noer MS, Soemyarso NA, Subandiyah K, Prasetyo RV, Alatas H, Tambunan T, et al., editors. Kompendium Nefrologi Anak. Jakarta: Badan penerbit IDAI; 2011. p. 207-22.

8. Woodward M, Frank D. Postnatal management of antenatal hydronephrosis. BJU Int. 2002;89:149-56.

9. Stefan C, Bulucea D. Urinary tract infection and urological abnormalities in children. Acta Medica Marisiensis. 2009;363-5.

10. Honkinen O, Jahnukainen T, Mertsola J, Eskola J, Ruuskanen O. Bacteremic urinary tract infection in children. Pediatric Infect Dis J. 2000;19:630-4.

11. Ladhani S, Gransden W. Increasing antibiotic resistance among urinary tract isolates. Arch Dis Child. 2003;88:4445.

12. Chang SL, Shortliffe LD. Pediatric urinary tract infections. Pediatr Clin North Am. 2006;53:379-400.

13. McKerrow W, Davidson-Lamb N, Jones PF. Urinary tract infection in children. Br Med J. 1984;289:299-303.

14. Najib KH, Fallahzadeh E, Fallahzadeh MK, Erjanee A. Renal scar formation in children with recurrent urinary tract 
Diana Bancin et al: A rare case of congenital hypertrophy of the verumontanum

infections. Iranian Red Crescent Med J. 2009;11:93-95.

15. Jakobsson B, Berg U, Svensson L. Renal scarring after acute pyelonephritis. Arch Dis Child. 1994;70:111-5.

16. Orellana P, Baquedano P, Rangarajan V, Zhao JH, Eng ND, Fettich J, et al. Relationship between acute pyelonephritis, renal scarring, and vesicoureteral reflux. Results of a coordinated research project. Pediatr Nephrol. 2004;19:11226.

17. Jacobson SH, Eklof O, Eriksson CG, Lins LE, Tidgren B, Winberg J. Development of hypertension and uraemia after pyelonephritis in childhood: 27 year follow up. BMJ. 1989;299:703-6.

18. Sarhan O, El-Ghoneimi A, Hafez A, Dawaba M, Ghali A, Ibrahiem el-H. Surgical complications of posterior urethral valve ablation: 20 years experience. J Pediatr Surg. 2010;45:2222-6.

19. Downs SM. Technical report: urinary tract infections in febrile infants and young children. The Urinary Tract Subcommittee of the American Academy of Pediatrics Committee on Quality Improvement. Pediatrics. 1999;103:1-60.

20. Smellie JM, Normand IC, Katz G. Children with urinary infection: a comparison of those with and without vesicoureteric reflux. Kidney Int. 1981;20:717-22.

21. Uthup S, Binitha R, Geetha S, Hema R, Kailas L. A followup study of children with posterior urethral valve. Indian J Nephrol. 2010;20:72-5.

22. Garin EH, Olavarria F, Garcia Nieto V, Valenciano B, Campos A, Young L. Clinical significance of primary vesicoureteral reflux and urinary antibiotic prophylaxis after acute pyelonephritis: a multicenter, randomized, controlled study. Pediatrics. 2006;117:626-32.

23. Conway PH, Cnaan A, Zaoutis T, Henry BV, Grundmeier, Keren R. Recurrent urinary tract infections in children: risk factors and association with prophylactic antimicrobials. JAMA. 2007;298:179-86.

24. American Academy of Pediatrics. Committee on Quality Improvement. Subcommittee on Urinary Tract Infection. Practice parameter: the diagnosis, treatment, and evaluation of the initial urinary tract infection in febrile infants and young children. Pediatrics. 1999;103:843-52.

25. Shortliffe LM. Urinary tract infection in infants and children. In: Wein AJ, Kavoussi LR, Novick AC, Partin AW, Peters CA, editors. Campbell-Walsh Urology. 9th ed. Philadelphia: WB Saunders; 2007. p. 1846-84.

26. Nagler EV, Williams G, Hodson EM, Craig JC. Interventions for primary vesicoureteric reflux. Cochrane Database Syst Rev. 2011;6:1-95.

27. Lopez Pereira P, Espinosa L, Martinez Urrutina MJ, Lobato R, Navarro M, Jaureguizar E. Posterior urethral valves: prognostic factors. BJU Int. 2003;91:687-90.

28. Denes ED, Barthold JS, Gonzalez RE. Early prognostic value of serum creatinine levels in children with posterior urethral valves. J Urol. 1997;157:1441-3.

29. Onuora VC, Mirza K, Koko AH, Al Turki M, Meabed AH, Al Jawini N. Prognostic factors in Saudi children with posterior urethral valves. Pediatr Nephrol. 2000;14:221-3. 